\title{
Benefits of annual chemotherapeutic control of schistosomiasis on the development of protective immunity
}

Tawanda J. Chisango ${ }^{1}$, Bongiwe Ndlovu ${ }^{1}$, Arthur Vengesai ${ }^{2}$, Agness Farai Nhidza', Edson P. Sibanda ${ }^{3}$, Danai Zhou ${ }^{4}$, Francisca Mutapi ${ }^{5}$ and Takafira Mduluza ${ }^{1,2^{*}}$ (i)

\begin{abstract}
Background: Schistosomiasis is a devastating parasitic disease. The mainstay of schistosomiasis control is by praziquantel treatment. The study aimed to determine benefits of annual chemotherapy of schistosomiasis on development of protective immunity in school children in a selected endemic rural area in Zimbabwe.

Methods: Urine specimens from 212 school children (7-13 years) were collected and examined to determine prevalence, intensity and reinfection of S.haematobium at baseline, 6 weeks and 2 years following annual rounds of praziquantel treatment. Blood samples from the participants were assayed for total and S. haematobium (Sh13)-specific antibodies before and 2 years after annual rounds of treatment.

Results: Annual treatment reduced the prevalence of $S$. haematobium infection $(p<0.05)$ from $23.1 \%$ at baseline to 0 . $47 \%$ after 2 years. Overall cure rate was $97.8 \%$. Intensity of infection declined $(p<0.05)$ from 15.9 eggs/10 $\mathrm{ml}$ urine at baseline to 2 eggs $/ 10 \mathrm{ml}$ urine. After two years, overall rate of reinfection was $0.96 \%$. At baseline, total lgG4 was higher in $\mathrm{S}$. haematobium-infected children $(p=0.042)$, while all other immunoglobulins were within normal ranges. There was an increase in total $\operatorname{lgG} 2(p=0.044)$ levels and a decrease in total $\operatorname{lgG} 4(p=0.031)$ levels 2 years post-treatment; and no significant changes in other total immunoglobulins. Schistosoma-infected children at baseline showed an increase in anti-Sh13 IgG1 $(p=0.005)$ and a decrease in Sh13 IgG4 levels $(p=0.012)$ following treatment.

Conclusion: Annual praziquantel treatment delivered to school children over 2 years significantly reduce prevalence, intensity of infection and reinfection of S. haematobium infection. Treatment was also observed to cause a reduction in schistosome-specific blocking lgG4 and an increase in Schistosoma-specific protecting lgG1.
\end{abstract}

Keywords: Praziquantel, Schistosomiasis, MDA, Treatment, Antibodies, Immunity

\section{Background}

Schistosomiasis is a devastating neglected tropical disease (NTD) that begins when infective cercariae from freshwater snails pierce the skin as a result of exposure to infested water [1]. Such a scenario is typical in resource limited settings with poor sewage disposal and inadequate supply of clean water. It is estimated that over 250 million people are infected with schistosomiasis, worldwide. Approximately 93\% of the infected people reside in sub-Saharan Africa [2],

\footnotetext{
*Correspondence: tmduluza@yahoo.com

'School of Laboratory Medicine and Medical Sciences, College of Health Sciences, University of KwaZulu-Natal, Durban, South Africa

2Biochemistry Department, University of Zimbabwe, 630 Churchill Ave, Mount Pleasant, Harare, Zimbabwe

Full list of author information is available at the end of the article
}

where school children carry the heaviest burden and account for the highest prevalence and heavy intensity of schistosome infections [3]. Children are mainly infected due to their higher rates of water contact activities in open water sources and immature immunological status $[4,5]$. The infected children usually suffer from haematuria, dysurea, several nutritional deficiencies and anaemia that affect growth, decreased physical performance and impaired memory and cognition when the schistosome infection intensity becomes heavy $[6,7]$.

The Ministry of Health and Child Care in Zimbabwe included schistosomiasis in the 2009-2013 National Health Strategy in 2009 underlining the importance and the urgent need to control the disease. A nationwide

(c) The Author(s). 2019 Open Access This article is distributed under the terms of the Creative Commons Attribution 4.0 International License (http://creativecommons.org/licenses/by/4.0/), which permits unrestricted use, distribution, and reproduction in any medium, provided you give appropriate credit to the original author(s) and the source, provide a link to the Creative Commons license, and indicate if changes were made. The Creative Commons Public Domain Dedication waiver (http://creativecommons.org/publicdomain/zero/1.0/) applies to the data made available in this article, unless otherwise stated. 
schistosomiasis survey was conducted in Zimbabwe and the overall prevalence of $S$. haematobium was reported as $18.0 \%$ while that of $S$. mansoni was $7.2 \%$. Manicaland region, where this study was conducted has a moderate burden of the parasitic disease at $23.8 \%$ prevalence of schistosomiasis [7, 8].

Chemotherapeutic control using praziquantel is aimed particularly at school age children living in schistosomiasis endemic areas. The treatment and control measure for schistosomiasis has been recommended by the World Health Organization (WHO) [9] as an interim available control strategy, since no vaccines are as yet available. Praziquantel is a widely used drug for treating schistoisomiasis and very few cases of treatment failures have been reported. Generally praziquantel is easy to administer, safe, well tolerated, cheap, can reverse schistosome-related morbidity and is highly effective against the five schistosome species that infect humans [10, 11]. Mass drug administration using the anti-helminthic drug praziquntel has been the major focus of recent control efforts [12], with the principal aim of reducing morbidity and clearing sources of recontaminating the environment. Scaling up of mass drug administration has been proposed in the WHO's strategic plan of 2012 as a way of managing schistosomiasis morbidity by 2020 [13]. Schools have been targeted for mass treatments because of the increased benefits of reducing infection burdens in children compared to adults and the simplicity of providing treatment [14]. Many studies have shown that praziquantel drastically reduces morbidity and transmission of schistosomiasis especially in low-to-moderate transmission areas where the risk of reinfection is generally low [15-17], despite a few reports of treatment failures $[18,19]$.

Although praziquantel is efficient in removing active infection, it does not have an effect on the developing immature worms. As a result, reinfections have been reported and still remains as a challenge in communities where it is unavoidable to get in contact with water infested with snails carrying the S. haematobium cercariae [20]. In high transmission endemic areas, the first treatment using praziquantel must be divided over weeks to also target the immature worms and repeatedly administered over rounds of annual treatment for a period in order to maintain low reinfection levels [21], however the long-term effects on infection dynamics and immune status are not yet fully understood. In our current study, repeated annual rounds of praziquantel were administered to children attending Bandanyenje primary school. Although the overall prevalence and distribution of schistosomiasis have been reported in the province, less emphasis has been given to the effect of repeated rounds of praziquantel and the subsequent prevalence, intensity of infection and re-infection rates in Bandanyenje. Information on the efficacy of praziquantel and the infection rates may help in evaluating policies and strategies that guide schistosomiasis control activities in the district. Thus, we assessed the effect of annual treatment with praziquantel over 2 years on the prevalence and reinfection rates in school children attending Bandanyenje primary school in Manicaland province of Zimbabwe. The intensity of Schistosoma infection, using the major symptom, haematuria, as an indicator of morbidity, was also evaluated.

Several studies have reported the chemotherapy-induced changes in responses to schistosome infection $[13,22,23]$. Frequent treatments are thought to enhance the development of protective immune responses. Studies of the effects of chemotherapy on other helminths indicate that the drug treatment can facilitate the development of resistance to re-infection through enhanced production of protective antibodies. Key information on the humoral immune status of individuals can be determined routinely by measuring total immunoglobulin levels. Several studies have realized the association between total immunoglobulins in chronic diseases associated with inflammation such as diabetes [24, 25]. Very little has been done on the association between the levels of total immunoglobulins and schistosomiasis, which is also a chronic disease that is associated with inflammation. Indeed treatment of schistosomiasis has shown to be associated with subsequent changes in humoral and cellular immune responses although focus has been mainly on Schistosoma- specific antibodies [22]. Antibodies such as IgE, IgM and IgG1 have been shown to be associated with resistance against schistosomiasis (4, 18-20), while IgG2 and IgG3 have been shown to kill schistosomula in the presence of activated eosinophils (21). IgG4 has been suggested as a modulator for the anaphylactic responses associated with $\operatorname{IgE}(22,23)$ while IgA responses have been shown to be associated with reduced parasite fecundity (24). Analysis of such changes in the context of both total and schistosme-specific antibodies will assist in interpreting the differences that occur in children living in endemic areas as well as improving current understanding of the development of acquired immunity to schistosome infections and contributing towards vaccine development. In order to establish the relationships between total serum immunoglobulins and S.haematobium-specific antibodies and to better understand antibody turnover after praziquantel treatment we quantitatively measured the total immunoglobulins and Schistosoma-specific antibody profiles in school children before and after two annual rounds of treatment using praziqunatel.

\section{Methods}

\section{Study area and population}

The study was carried out in Bandanyenje Primary School located in the Manicaland Province in Zimbabwe. The school is approximately $217 \mathrm{Km}$ South-East of Harare 
with latitude and longitude of $7^{\circ} 1^{\prime} \mathrm{N} 38^{\circ} 35^{\prime} \mathrm{E}$. Villagers living in Bandanyenje community depend on perennial rivers as their water source thus indicating an increased likely exposure of the majority of their population to infection. The study population comprised of 212 (105 boys and 107 girls) aged between 7 and 13 years, who were permanent residents of the area.

\section{Parasitology and blood sampling}

A school-based longitudinal intervention study was conducted and involved examination and treatment of the study population at baseline, 6 weeks and at 2 years follow up surveys. Stool and urine samples were collected over three consecutive days at baseline and at follow up, for each examination time-point. The urine samples were processed for urinary schistosomiasis using the filtration technique following Mott et al., 1982 [26] method. The stool samples were processed following the Kato Katz technique and Formol-ether concentration method as modified by Peters et al., (1980) [27]. A sample with the number of eggs greater than zero in $10 \mathrm{ml}$ of urine was classified as being $S$. haematobium-positive. Those found to be infected with $S$. mansoni were excluded from the study; however the sampling site was observed to have very low $S$. mansoni transmission. The prevalence was defined as the number of infected children with $S$. haematobium over the total number screened. Intensity of S.haematobium infection was expressed as number of eggs per $10 \mathrm{ml}$ (ep10ml) of urine. Infection intensities were classified into three categories: (1) light infections $(<10$ ep10ml),

(2) moderate infections $(10 \mathrm{ep} 10 \mathrm{ml}<\mathrm{x}<50 \mathrm{ep} 10 \mathrm{ml}$ and

(3) heavy infections ( $\geq 50 \mathrm{ep} 10 \mathrm{ml})$. Blood samples were obtained from the children, the serum separated and used to determine total immunoglobulins and antibody profiles against $S$. haematobium 13 (Sh13).

\section{Determination of plasma Total antibody profiles}

About $50 \mu \mathrm{l} 1 \mathrm{x}$ beads were added to a 96 well micro titer plate and washed $2 \mathrm{x}$ with the Bio-Rad wash buffer, (Cat \#, 10,014,939). The standards, samples and controls were diluted (Bio-Rad Antibody diluent, (Cat \#, 35,002,989) and $50 \mu \mathrm{l}$ added to the wells and incubated in the dark at room temperature with shaking at $850 \mathrm{rpm}$ for $1 \mathrm{~h}$. After incubating the beads, samples, standards, blank and controls; the plates were washed three times with $100 \mu \mathrm{l}$ wash buffer. $1 \mathrm{x}$ detection antibodies were added to the assay plate and incubated in the dark for $30 \mathrm{~min}$ with shaking at 850 $\mathrm{rpm}$. The plate was washed $3 \mathrm{x}$ and Streptavidin - PE (Cat \#, L9703897) was added. The assay plate was incubated for $10 \mathrm{~min}$ at room temperature with shaking at $850 \mathrm{rpm}$. The plate was washed $3 \mathrm{x}$ and the beads (Bio-Rad Cat \#, 171-304,040) were re-suspended for plate reading. The
Bio-plex manager software was used running the assay, data acquisition and analysis.

\section{Determination of S. haematobium (Sh13) specific antibodies}

The recombinant Sh13 protein was used for the immuno-detection of specific antibodies patterns among 147 school children aged 7-13 years old and exposed to $S$. haematobium. The anti-schistosome recombinant vaccine candidate (Sh13) has been postulated to prevent worms from pairing thereby preventing them from laying eggs. The Sh13 cDNA sequence has been described and deposited in the Genbank database at the NCBI under the bankit no DQ709821. An indirect ELISA was optimized and used to quantify the amount of antibodies IgG1, IgG4 and IgE produced directly against the Sh13 antigen. Both pre- and post -treatment samples were analyzed on the same plate. Briefly, the plates were coated with Sh13 antigen at $5 \mathrm{ng} / \mathrm{ml}$ over night at $4{ }^{\circ} \mathrm{C}$. Diluted plasma was added at 1:10 for IgG4, 1:50 for IgG1 and IgE, dilutions. Monoclonal anti-human IgG conjugated to peroxidase was used to detect the presence of anti-Sh13 IgG1, IgG4 and IgE antibodies. Six microwells were reserved for positive, negative controls and background blank containing MBP in duplicate, that was used in the preparation of the Sh13 antigen. This was due to the Sh13 suspension contain MBP. About $100 \mu \mathrm{l}$ of the OPD substrate was added to each well containing horse reddish peroxidase enzyme and incubated for $30 \mathrm{~min}$ in the dark. The enzyme reaction was stopped with sulphuric acid and the absorbance was read at $450 \mathrm{~nm}$ with 630 as reference wavelength.

\section{Haematuria}

As a measure for schistosome-induced pathology, haematuria was determined in urine samples collected at baseline and 2 years following treatment with $40 \mathrm{mg} / \mathrm{kg}$ praziquantel. A Combur-Test (Roche Diagnostics GmbH, Mannheim, Germany) reagent strip was used to detect the presence of blood in the urine.

\section{Treatment}

Treatment was carried out by qualified health teams of trained nurses and medical officers as part of the MDA treatment campaign. All school children were treated with a single dose of $40 \mathrm{mg} / \mathrm{kg}$ praziquantel at baseline and thereafter without considering the infection status after 1 and 2 years.

\section{Ethical considerations}

Blood and urine specimens were obtained from willing children who agreed to participate in the study following the signing of informed consent forms by their parents 
and guardians. Ethical approval for the study was obtained from the Medical Research Council of Zimbabwe (MCRZ) (Approvals MRCZ/A/1710 and MRCZ/A/ 1958). In addition, Provincial Medical and Education Directors, councillors and village head-men granted permission for the study.

\section{Data analysis}

Data was entered into the computer using Microsoft Excel spreadsheet and exported to SPSS for windows version 16.0 (SPSS Inc., Chicago, Illinois, USA). The Pearson chisquare test was used to compare the differences in the prevalence of infections and arithmetic egg counts as well as to assess the association with age and gender. Student $\mathrm{t}$-test was used to compare differences in the prevalence and intensity of infection (eggs $/ 10 \mathrm{ml}$ urine) before and after treatment. A value of $p<0.05$ was considered as statistically significant. To determine if there was a significant difference between pre-and post-treatment of the total immunoglobulin as well as the specific antibody profiles a comparison of means using a paired t-test was conducted. The hypothesis that there were no differences between pre-treatment and 2 years post treatment antibody profiles was tested. $P$ value set at $p<0.05$.

\section{Results}

\section{Baseline prevalence, intensity and reinfection}

Of the 233 school children from Bandanyenje primary school who volunteered and provided urine and stool samples, S. mansoni was diagnosed in (9\%) 21/233 and soil transmitted helminths in $0.4 \%(1 / 233)$ and these children were not included in the study. The remaining 212 (105 boys and 107 girls) aged between 7 and 13 were recruited in the study and were successfully traced and re-examined at both follow-ups with complete sets of longitudinal parasitological data on S. haematobium infection. The overall pre-treatment prevalence of $S$. haematobium infection was 49 (23.1\%) with 20 (19\%) boys and $29(27.2 \%)$ girls as determined using the urine filtration technique. The age group of $10-13$ years as well as the girls had the highest prevalence 25.6 and $27.1 \%$, respectively. However the differences in infection status between age groups $\left(X^{2}=0.158, P=0.691\right)$ and boys and girls $\left(\chi^{2}=1.891, p=0.169\right)$ were not significant (Table 1). The majority of infected children in the both age groups had light infections with more heavy infections being observed in the 7-9 age (10.5\%) group than the $6.7 \%$ in the $10-13$ age group. However the intensity of infection had no age group $\left(x^{2}=2.594, p=0.273\right)$ or sex-related pattern $\left(X^{2}=0.297, p=0.862\right)$. The proportion of boys $(10 \%)$ that had a heavy infection was greater than girls $(6.9 \%)$ though not statistically significant (Table 1).

There was an overall decline in S. haematobium prevalence from $23.1 \%$ at baseline to $0.47 \% \%$ at 6 weeks post-treatment and, $0.47 \% 2$ years post-treatment, an overall $87.1 \%$ reduction over 2 years $(p<0.05)$. A total of 211 (99.5\%) children were egg negative after treatment. Boys had a higher baseline S. haematobium prevalence, although it was not statistically significant. The S. haematobium prevalence significantly decreased to $0.47 \%$ $(\mathrm{p}<0.05 \%)$ following 2 years of 3 annual rounds of praziquantel treatment. The overall Cure Rate (CR) was $97.8 \%$ and egg infection intensity was $15.9 \mathrm{egg} /$ $10 \mathrm{ml}$ urine at baseline and reduced to $2 \mathrm{egg} / 10 \mathrm{ml}$ urine 2 years post-treatment (Table 2). The study of reinfection involved the 211 children who were cured 6 weeks after the first praziquantel treatment. Of these $S$. haematobium negative, only 1 boy $(0.96 \%)$ contracted the infection 2 years after the 6 week treatment (Table 3). Apparently this was a boy who had a heavy infection (60 eggs $/ 10 \mathrm{ml}$ ) at baseline.

\section{Haematuria}

Haematuria was detected in $32(15.1 \%)$ of the study participants of which 23 (71.9\%) were S. haematobium infected. The presence of $S$. haematobium eggs showed statistically significant association $\left(\chi^{2}=20.38, p<0.05\right)$ with haematuria whilst there was no association between sex and haematuria $\left(X^{2}=0.08, p=0.929\right)$. At 2 years post treatment, the extent of haematuria decreased from 100 to $0 \%$.

\section{Total and S. haematobium specific antibodies}

Baseline levels of total IgG4 were significantly higher in $S$. haematobium infected compared to S. haematobium

Table 1 Baseline prevalence and intensity of S. haematobium infection

\begin{tabular}{|c|c|c|c|c|c|c|c|c|c|}
\hline Parameter & $\begin{array}{l}\text { S. haematobium } \\
\text { infected }\end{array}$ & $\begin{array}{l}\text { S. haematobium } \\
\text { uninfected }\end{array}$ & $x^{2}$ & $P$ value & Light Infection & Moderate Infection & Heavy Infection & $x^{2}$ & $P$ value \\
\hline Sex & & & 1.891 & 0.169 & & & & 0.297 & 0.862 \\
\hline Boys & $20(19 \%)$ & $85(81 \%)$ & & & $11(55 \%)$ & $7(35 \%)$ & $2(10 \%)$ & & \\
\hline Girls & $29(27.1 \%)$ & 78 (72.9\%) & & & $20(69 \%)$ & $7(24.1 \%)$ & $2(6.9 \%)$ & & \\
\hline Age Group & & & 0.158 & 0.691 & & & & 2.594 & 0.273 \\
\hline $7-9$ & 19 (20\%) & $76(80 \%)$ & & & $13(68.4)$ & $4(21.1 \%)$ & $2(10.5 \%)$ & & \\
\hline $10-13$ & 30 (25.6\%) & 87 (74.4\%) & & & $18(60 \%)$ & 10 (33.3\%) & 2 (6.7\%) & & \\
\hline
\end{tabular}


Table 2 Prevalence, cure rate and egg intensity at baseline, 6 weeks and 2 years following annual treatment with praziquantel

\begin{tabular}{llll}
\hline Variable & Baseline & $\begin{array}{l}6 \text { weeks post } \\
\text { treatment }\end{array}$ & $\begin{array}{l}2 \text { years post } \\
\text { treatment }\end{array}$ \\
\hline $\begin{array}{l}\text { Prevalence } \\
\text { Cure rate }\end{array}$ & $49(23.1 \%)$ & $\begin{array}{l}1(0.47 \%) \\
98 \%\end{array}$ & $1(0.47 \%)$ \\
Boys & & $1(0.47 \%)$ & $1(0.47 \%)$ \\
Cure rate & $20(19 \%)$ & $95 \%$ & $94.7 \%$ \\
Girls & $29(27.1 \%)$ & 0 & 0 \\
Cure rate & & $100 \%$ & $100 \%$ \\
$7-9$ & $19(20 \%)$ & $1(0.47 \%)$ & $1(0.47 \%)$ \\
Cure rate & & $94.7 \%$ & $94.4 \%$ \\
$10-13$ & $30(25.6 \%)$ & 0 & 0 \\
Cure rate & & $100 \%$ & $100 \%$ \\
Eggs per $10 \mathrm{ml}$ & 15.9 & 3 & 2 \\
\hline
\end{tabular}

negative children (Fig. 1). At 2 years after treatment, serum IgG2 increased and serum IgG4 tended to decreased post treatment with praziquantel $(p=0.044$ and 0.031 , respectively). There were no significant changes in total plasma IgG1, IgG3, IgM and IgA. Levels of S. haematobium IgG4 were significantly higher in S. haematobium infected when compared to $S$. haematobium negative $(p<0.05)$. Following chemotherapy, significant decreases of $S$. haematobium IgG4 were observed. Specific S. haematobium-IgE levels before treatment were higher than the S. haematobium IgE levels though no significant changes were noted before and after treatment in both $S$. haematobium uninfected and infected children (Fig. 2). The protective S. haematobium IgG1 increased significantly in $S$. haematobium infected children following treatment.

\section{Discussion}

At baseline survey, the prevalence of S. haematobium infection in the study area was observed to be low at 23.1\% compared to other areas in Zimbabwe [8]. However, the prevalence was within the range of the average prevalence within the province (Manicaland, 23.8\%) as determined by a nationwide survey that was conducted by Midzi et al., (2014) [8]. The low prevalence of S. haematobium infection reported in this study could reflect

Table 3 Re-infection cases of S. haematobium post-praziquantel treatment

\begin{tabular}{clll}
\hline & $\begin{array}{l}\text { S. haematobium } \\
\text { infected }\end{array}$ & $\begin{array}{l}\text { S. haematobium } \\
\text { uninfected }\end{array}$ & Reinfection Cases \\
\hline 6 weeks & & $104(99.05 \%)$ & - \\
Boys & $1(0.95 \%)$ & $107(100 \%)$ & - \\
Girls & $0(0 \%)$ & $103(99.03 \%)$ & $1(0.96 \%)$ \\
2 years & & $107(100 \%)$ & $0(0 \%)$ \\
Boys & $1(0.95 \%)$ & & \\
Girls & $0(0 \%)$ & & \\
\hline
\end{tabular}

the on-going control efforts in the area. Lately, constant awareness campaigns advocated during the annual mass drug administration exercise compounded by improved health education in rural areas have been part of efforts by the Ministry of Health to control schistosomiasis which had been neglected for a long time. This could have contributed in decreased contact with infested waters by children in the area.

Infection intensity is a better indicator of morbidity associated with schistosomiasis than prevalence as it indirectly reflects the number of worms infecting the individual and it is also a more reliable marker of treatment success defined as the removal of egg-laying worms [28-32]. We observed a significant decline in prevalence after the first dose of treatment at 6 weeks exhibiting a satisfactory efficacy with praziquantel. In this study, our results demonstrated a significant impact of praziquantel in treatment of $S$. haematobium with cure rates of $97.8 \%(p<0.05 \%)$ following 2 years of repeated annual rounds of praziquantel treatment. This is comparable to findings of similar studies that have reported a higher efficacy of praziquantel when administered as two or three treatments spaced at certain time intervals $[14,33]$.

Total prevalence of re-infection 2 years post-treatment was $1 \%$. It has been hypothesized that, after infections and repeated rounds of praziquantel chemotherapy, humans slowly acquire protective immunity to $S$. haematobium leading to partial resistance to re-infection [34]. Treatment with praziquantel boosts immunoglobulin E (IgE) antibodies against adult worms which are associated with resistance to re-infection [17]. In contrast to our findings, other studies observed a rapid and high re-infection rate a few weeks following treatment especially in high transmission areas [35-37]. Presence of haematuria before treatment was correlated with the presence of S.haematobium eggs in urine. In response to treatment with single dose of praziquantel, haematuria fell from 100 to $0 \%$ at 2 years post- treatment (Table 4 ).

There is mounting evidence that anti-helminthic treatment using praziquantel not only transiently reduces infection, but also has longer term benefits in terms of morbidity control and the development of parasite-specific immune responses associated with resistance to re-infection $[18,38]$. It is widely accepted that the changes in Schistosoma-specific immune response occur following treatment of schistosomiasis with praziquantel $[7,38,39]$. Praziquantel penetrates the tegument of worm tissues and rapidly moves through damaging the tegument and causing paralysis of the worm [40]. The increase in antigens released from dying worms as a result of praziquantel induced-tegument damage is believed to trigger this change in both the cellular and humoral immune responses [41]. 


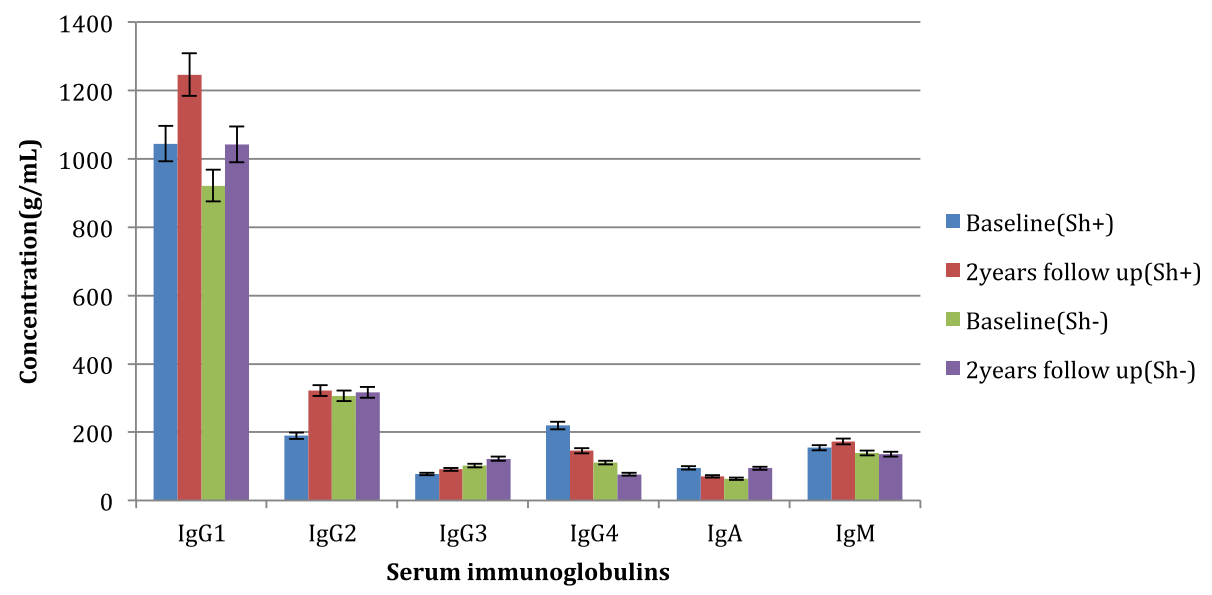

Fig. 1 Concentration of total antibodies at baseline and 2 years post annual praziquantel treatment

In this study following chemotherapy there were changes in both the total and S. haematobium-specific antibodies. There was a significant increase in total IgG2, total and S. haematobium-specific IgG1 and a significant decline in total and $S$. haematobium-specific IgG4 while there were no significant changes in all the other antibodies. Antibody responses against Sh13 were predominantly IgG3 and IgG1 isotypes indicating establishing a protective immunity compared to responses, which were predominantly IgG4 in the reinfected. Studies done in individuals with chronic schistosomiasis have revealed elevated levels of total immunoglobulins [42]. We observed an increase in both the total and specific IgG1 which was maintained over the 2 years, which suggest that IgG1 could have been stimulated by antigens produced from the worms after chemotherapy. Khalife et al., (1989) [45] demonstrated the eosinophildependent killing of schistosomula as a result of IgG1.
This could explain the significant increase of IgG1 following treatment with praziquantel and the significant clearance of infection at 6 weeks and thereafter 2 years later. The release of sub-surface antigens and a decline in egg counts following treatment result in stimulation of IgG1 production. A similar increase in specific IgG1 following chemotherapy was noted by Mutapi et al (1998) [48]. They observed an increase in IgG1 following treatment with praziquantel, which they attributed to a switch from IgA specific antibodies to IgG1 response that occurs in children. The potential mechanism for this switch is not fully understood, but it is believed that changes in cytokine levels in response to antigen release from damaged parasites may cause this isotype switch from IgA to IgG1 [23]. The switch occurs naturally as worms die but takes a long time as a result of life span of schistosomes. The switch is accelerated by the praziquantel treatment which actually causes partial

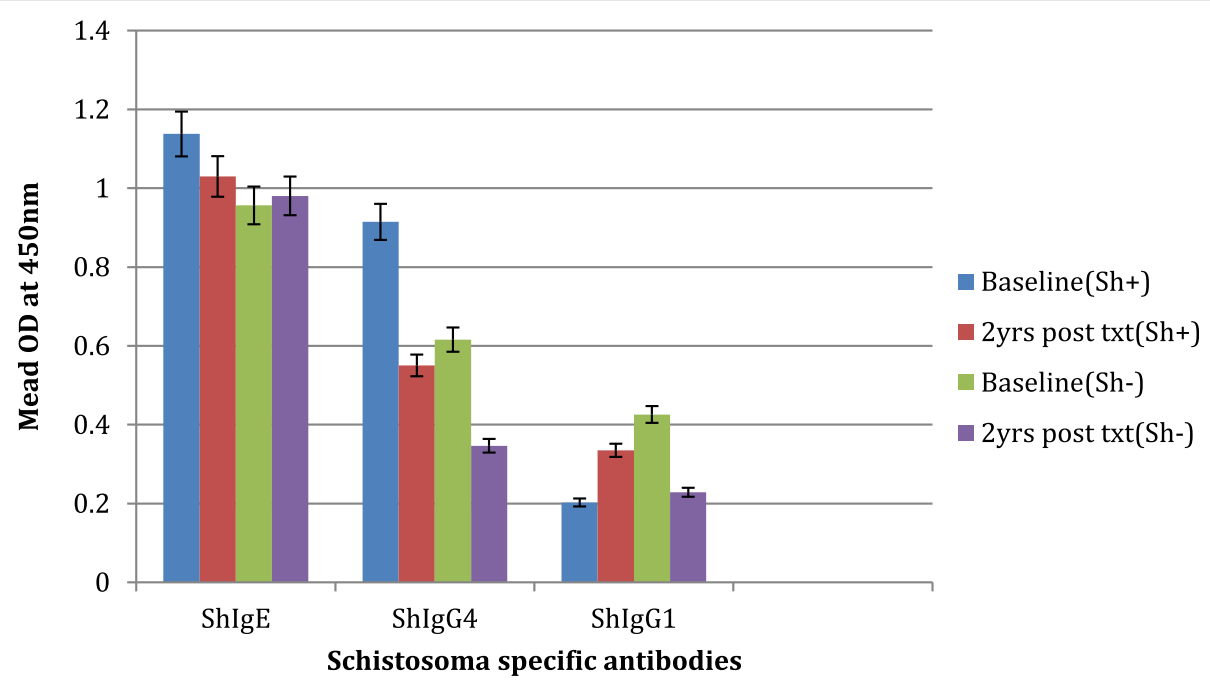

Fig. 2 Mean OD values of S. haematobium specific antibodies at baseline and 2 years post annual praziquantel treatment 
Table 4 Occurrence of haematuria at baseline and 2 years after praziquantel treatment

\begin{tabular}{lllll}
\hline & Before Treatment & & 2 years Post treatment \\
\hline & $\begin{array}{l}\text { S. haematobium } \\
\text { Infected }\end{array}$ & $\begin{array}{l}\text { S. haematobium } \\
\text { Uninfected }\end{array}$ & $\begin{array}{l}\text { S. haematobium } \\
\text { Infected }\end{array}$ & $\begin{array}{l}\text { S. haematobium } \\
\text { Uninfected }\end{array}$ \\
Boys & $9(45 \%)$ & $5(5.9 \%)$ & 0 & 0 \\
Girls & $14(48.3 \%)$ & $4(5.1 \%)$ & 0 & 0 \\
$7-9$ & $8(42.1 \%)$ & $3(3.9 \%)$ & 0 & 0 \\
$10-13$ & $15(50 \%)$ & $6(6.9 \%)$ & 0 & 0 \\
\hline
\end{tabular}

protection to reinfection as seen by the $1 \%$ reinfection rate 2 years post treatment noted in this study. The changing relationship between infection intensity and anti-Sh13 IgG3 levels post treatment is consistent with the profile of a protective immune response predicted from theoretical work and with protective immunity developing with cumulative experience of parasite antigens after rounds of MDA.

Most studies have demonstrated the protective role played by IgE, which surprisingly in this study showed no significant change in both the infected and non-infected group at baseline. Following treatment there were no significant changes $(p<0.05)$ in $\operatorname{IgE}$ in both $S$. haematobium infected and non infected (Fig. 1), though the levels remained higher than blocking IgG4 levels that decreased significantly following chemotherapy. Similar trends though in $S$. mansoni were observed by Walter et al., (2006) [49]. They demonstrated that following treatment, adult worm-specific IgG4 levels decreased, while worm-specific IgE are maintained at pre-treatment levels or increases even in children, who more readily become reinfected, treatment is less likely to increase the IgE/ IgG4 ratio. There is need therefore to carry out further studies especially taking into account cytokine levels which are key to facilitating the production of both the total and S. haematobium-specific antibodies.

In our study $S$. haematobium uninfected children had significantly lower levels $(p<0.05)$ of the blocking antibody IgG4 at baseline than the infected children, this was observed for both total and S. haematobium-specific IgG4 (Figs. 1 and 2). Blocking antibodies like IgG4 which have been observed to develop early in life have been shown to predispose children to infection. Studies on Schistosoma-infected populations have reported that anti-Schistosoma IgG4 levels in infected children are associated with higher parasite burdens and parasite susceptibility [43, 44]. IgG4 is known to interfere with IgE-induced mast cell and eosinophil degranulation through preventing the binding of IgE to the effector cells thereby preventing killing of schistosomula [45], IgG4 will also block IgG1 and IgG3 mediated killing of schistosomula by human eosinophils in vitro [34]. Elevated IgG4 levels observed in S. haematobium infection compared to uninfected children increase predisposition to infection. Following treatment there was a significant decrease $(p<0.05)$ in IgG4 highlighting the importance of praziquantel in lowering IgG4 which then results in a significant decline in infection at 6 weeks and 2 year post treatment. There is need therefore to carry out further studies especially taking into account cytokine levels which are key to facilitating the production of both the total and S. haematobium-specific antibodies.

\section{Conclusion}

This study confirms findings from previous work by other research groups that praziquantel treatment reduces S. haematobium egg burden and alters immune responses. There was a significant reduction in prevalence, intensity of infection and reinfection. Since the study area is a moderate zone of transmission without any specific past control program, treatment with praziquantel once every 2 years may keep the infection at low level of transmission. Two years of annual praziquantel treatment significant changes occured in total and Schistosoma-specific IgG1 as well as total and Schistosoma-specific IgG4 changes. These findings suggest long term health consequences of praziquntel effects in changing the overall protective immunity in the school children and benefits of the repeated mass drug administration.

\section{Additional file}

Additional file 1: 1. Parasitology egg counts pre and post treatment (Sh and Sm) and STH. 2. Sh13 Antibodies Optical Density measurements. 3. Total Antibodies Concentrations. 4. Acute Phase Proteins Concentratons. 5. Cytokine Concentrations. (XLSX $27 \mathrm{~kb}$ )

\section{Abbreviations \\ CR: Cure rate; MDA: Mass drug administration; NTD: Neglected tropical diseases; PZQ: Praziquantel; Sh13: S.haematobium 13; WHO: World Health Organization}

\section{Acknowledgements}

We are grateful to the participants who provided the samples used in the study. Also we are grateful to the technical assistance from the Biochemistry Department, University of Zimbabwe, during the fieldwork.

\section{Funding}

School of Laboratory Medicine and Medical Sciences, University of KwaZulu Natal, South Africa: Design of study, collection, analysis and interpretation of 
data and writing the manuscript. SCI and END Fund for the M\&E activities following the National MDA in Zimbabwe.

\section{Availability of data and materials}

Data supporting the conclusions of this article are included in the article. Further information on datasets used and/or analysed during the current study are available from the corresponding author upon reasonable request (Additional file 1).

\section{Authors' contributions}

TJC, FM, BN \& TM developed the field study design, immunoassays \& analyzed the data. While AV, AFN, EPS, DZ, FM \& TM conducted field and sampling work. TJC, AV, DZ, AFN \& BN conducted the laboratory assays. TJC, $\mathrm{BN}$ and TM conducted the initial statistical analyses. All authors read and approved the final manuscript.

\section{Ethics approval and consent to participate}

This manuscript draws from our work which received ethical approval from The Medical Research Council of Zimbabwe (MRCZ/A/1710 and MRCZ/A) 1958). All information pertaining to the discussion was obtained after written informed consent by the parents/guardian of the children participating in the study.

\section{Consent for publication}

Not applicable.

\section{Competing interests}

The authors declare that they have no competing interests.

\section{Publisher's Note}

Springer Nature remains neutral with regard to jurisdictional claims in published maps and institutional affiliations.

\section{Author details}

${ }^{1}$ School of Laboratory Medicine and Medical Sciences, College of Health Sciences, University of KwaZulu-Natal, Durban, South Africa. ${ }^{2}$ Biochemistry Department, University of Zimbabwe, 630 Churchill Ave, Mount Pleasant, Harare, Zimbabwe. ${ }^{3}$ Scientific and Industrial Research and Development Centre, 1574 Alpes Road, Box, Harare 6640, Zimbabwe. ${ }^{4}$ Medical Laboratory Sciences, College of Health Sciences, University of Zimbabwe, Harare, Zimbabwe. ${ }^{5}$ Institute of Immunology \& Infection Research, University of Edinburgh, Ashworth Laboratories, King's Buildings, Charlotte Auerbach Road, Edinburgh EH9 3FL, UK.

\section{Received: 27 October 2017 Accepted: 13 February 2019} Published online: 04 March 2019

\section{References}

1. Fenwick A, Savioli L, Engels D, Robert Bergquist N, Todd MH. Drugs for the control of parasitic diseases: current status and development in schistosomiasis. Trends Parasitol. 2003;19:509-15.

2. Steinmann P, Keiser J, Bos R, Tanner M, Utzinger J. Schistosomiasis and water resources development: systematic review, meta-analysis, and estimates of people at risk. Lancet Infect Dis. 2006;6(7):411.

3. Hotez PJ, Pecoul B, Rijal S, Boehme C, Aksoy S, Malecela M, Tapia-Conyer R, Reeder JC. Eliminating the Neglected Tropical Diseases: Translational Science and New Technologies. PLoS Negl Trop Dis. 2016;10(3):e0003895. https://doi.org/10.1371/journal.pntd.0003895.

4. Engels D, Chitsulo L, Montresor A, Savioli L. The global epidemiological situation of schistosomiasis and new approaches to control and research. Acta Trop. 2002:82:139-46.

5. Mutapi F, Burchmore R, Mduluza T, Midzi N, Turner CM, Maizels RM. Agerelated and infection intensity-related shifts in antibody recognition of defined protein antigens in a schistosome-exposed population. J Infect Dis. 2008;198:167-75.

6. Koukounari A, Gabrielli AF, Toure S, Bosque-Oliva E, Zhang Y. Schistosoma haematobium infection and morbidity before and after large-scale administration of praziquantel in Burkina Faso. J Infect Dis. 2007;196:659-69.

7. Midzi N, Mduluza T, Chimbari MJ, Tshuma C, Charimari L, Mhlanga G, Manangazira P, Munyati SM, Phiri I, Mutambu SL, Midzi SS, Ncube A Muranzi LP, Rusakaniko S, Mutapi F. Distribution of schistosomiasis and soil transmitted helminthiasis in Zimbabwe: towards a National Plan of action for control and elimination. PLoS Negl Trop Dis. 2014;8(8):e3014. https://doi. org/10.1371/journal.pntd.0003014.

8. World Health Organization. Schistosomiasis: number of people treated worldwide in 2013. Weekly Epidemiol Rec. 2015;5:25-32.

9. Doenhoff MJ, Cioli D, Utzinger J. Praziquantel: mechanisms of action, resistance and new derivatives for schistosomiasis. CurrOpin Infect Dis. 2008; 21:659-67.

10. Global Burden of Disease Study 2013 Collaborators. Global, regional, and national incidence, prevalence, and years lived with disability for 301 acute and chronic diseases and injuries in 188 countries, 1990-2013: a systematic analysis for the Global Burden of Disease Study 2013. Lancet. 2015; 386(9995):743-800.

11. Webster M, Fallon PG, Fulford AJC, Butterworth AE, Ouma JH, Kimani G, Dunne DW. Effect of praziquantel and oxamniquine treatment on human isotype responses to Schistosoma mansoni: elevated IgE to adult worm. Parasite Immunol. 1997;19:333-5.

12. Kabatereine NB, Brooker S, Koukounari A, Kazibwe F, Tukahebwa EM, Fleming FM, Zhang YB, Webster JP, Stothard JR, Fenwick A. Impact of a national helminth control programme on infection and morbidity in Ugandan school children. Bull World Health Organ. 2007;85:91-9.

13. Ahmed AM, Abbas H, Mansour FA, Gasim Gl, Adam I. Schistosoma haematobium infections among school children in Central Sudan one year after treatment with praziquantel. Parasites Vectors. 2012;5:108.

14. Campagne G, Garba A, Barkire H, Vera C, Sidiki A, Chippaux JP. Continued ultrasonic follow-up of children infected with Schistosoma haematobium after treatment with praziquantel. Tropical Med Int Health. 2001;6:24-30.

15. Webster BL, Diaw OT, Seye MM, Faye DS, Stothard JR, Sousa-Figueiredo JC. Praziquantel treatment of school children from single and mixed infection foci of intestinal and urogenital schistosomiasis along the Senegal River basin: monitoring treatment success and re-infection patterns. Acta Trop. 2013;128(2):292-302.

16. Stelma F, Talla I, Sow S, Kongs A, Niang M, Polman K, et al. Efficacy and side effects of praziquantel in an epidemic focus of Schistosoma mansoni. Am J Trop Med Hyg. 1995;53:167-70.

17. Wang $W$, Wang $L$, Liang YS. Susceptibility or resistance of praziquantel in human schistosomiasis: a review. Parasitol Res. 2012;111:1871-7.

18. Chan MS, Nsowah-Nuamah NNN, Adjei S, Wen ST, Hall A, et al. Predicting the impact of school-based treatment for urinary schistosomiasis given by the Ghana Partnership for Child Development. Trans R Soc Trop Med Hyg 1998;92:386-9.

19. Grogan J, Kremsler P, Deelder AJ, Yazdanbakhsh M. Elevated proliferation and interleukin-4 from CD4+ cells after chemotherapy in human Schistosoma haematobium infection. Eur J Imm. 1996;26:1365-70.

20. Mutapi F, Ndhlovu PD, Hagan P. Chemotherapy accelerates the development of acquired immune responses to Schistosoma haematobium infection. J Infect Dis. 1998;18:289-93.

21. Rodriguez-Segade S, Camiña MF. CarneroA. High serum IgA concentrations in patients with diabetes mellitus: age-wise distribution and relation to chronic complications. Clin. Chem. 1996:42:1064-7.

22. Hagan P, Blumenthal UJ, Dunn D, Simpson AJG, Wilkins HA. Human IgE, IgG4 and resistance to reinfection with Schistosoma haematobium. Nature. 1991:349:243-5

23. Khalife J, Dunne DW, Richardson BA, et al. Functional role of human IgG subclasses in eosinophil mediated killing of schisto- somula of Schistosoma mansoni. J Immunol. 1989;142:4422-7.

24. Holfsetter M, Poindexer RW, Ruiz-Tiben E, Ottesen EA. Modulation of the host response in human schistosomiasis. III. Blocking antibodies specially inhibit immediate hypersensitivity responses to parasite antigens. Immunology. 1982;46:777-85.

25. Rihet $P$, Demeure CE, Dessein AJ, Bourgois A. Strong serum inhibition of specific lgE correlated to competing lgG4, revealed by a new methodology in subjects from a S. Mansoni endemic area. Eur J Immunol. 1992;22:2063-70.

26. Mott KE, Baltes R, Bambagha J, Baldassini B. Field studies of the reusable polyamide filter for detection of $\mathrm{S}$. Haematobium eggs by urine filtration. Propernmedlizin and Parasitologie. 1982;33:227-8.

27. Peters PA, El Alamy M, Warren KS, Mahmoud AA. Quick Kato smear for field quantification of Schistosoma mansoni eggs. Am J Trop Med Hyg. 1980;29: 217-9.

28. Lo NC, Lai YS, Karagiannis-Voules DA, Bogoch II, Coulibaly JT, Bendavid E, Utzinger J, Vounatsou P, Andrews JR. Assessment of global guidelines for 
preventive chemotherapy against schistosomiasis and soil-transmitted helminthiasis: a cost-effectiveness modeling study. Lancet Infect Dis. 2016; 16(9):1065-75.

29. Geleta S, Alemu A, Getie S, Mekonnen Z, Erko B. Prevalence of urinary schistosomiasis and associated risk factors among Abobo primary school children in Gambella regional state, southwestern Ethiopia: a cross sectional study. Parasit Vectors. 2015;8(1):215.

30. Botros S, Sayeda H, Amera N, El-Ghannama M, Bennettb JL, Day TA. Current status of sensitivity to praziquantel in a focus of potential drug resistance in Egypt. Int J Parasitol. 2005;35:787-91.

31. Davis A. Clinical trials in parasitic diseases. Trans R Soc Trop Med Hyg. 2004; 98:139-41

32. Jordan P, Webbe G. In: Jordan P, Webbe G, Sturrock RF, editors. Epidemiology. Human schistosomiasis. Wallingford: CAB International; 1993. p. 87-158.

33. Garba A, Campagne G, Tassie JM, Barkire A, Vera C, Sellin B, et al. Long-term impact of a mass treatment by praziquantel on morbidity due to Schistosoma haematobium in two hyperendemic villages of Niger. Bull SocPatholExot. 2004;97:7-11.

34. Stelma FF, Sall S, Daff B, Sow S, Niang M, Gryseels B. Oxamniquine cures Schistosoma mansoni infection in a focus in which cure rates with praziquantel are unusually low. J Infect Dis. 1997;176:304-7.

35. Gray DJ, Ross AG, Li YS, McManus DP. Diagnosis and management of schistosomiasis. BMJ. 2011;342:d2651.

36. Mduluza T, Ndhlovu PD, Madziwa TM, Midzi N, Zinyama R, Turner CMR, Chandiwana SK, Nyazema N, Hagan P. The impact of repeated treatment with Praziquantel of schistosomiasis in children under six years of age living in an endemic area for Schistosoma haematobium infection. Mem Inst Oswaldo Cruz. 2001;96:157-64.

37. N'Goran EK, Utzinger J, N'Guessan AN, Müller I, Zamblé K, Lohourignon KL, et al. Reinfection with Schistosoma haematobium following school-based chemotherapy with praziquantel in four highly endemic villages in Côte d'Ivoire. Tropical Med Int Health. 2001;6(10):817-25.

38. Mott KE, Dixon H, Osei-Tutu E, England EC, Davis A. Effect of Praziquantel on hematuria and proteinuria in urinary schistosomiais. Am J Trop Med Hyg. 1985;34(6):1119-26.

39. Stephenson LS, Latham MC, Kinoti SN, Oduori ML. Sensitivity and specificity of reagent strips in screening of Kenyan children for Schistosoma haematobium infection. Am J Trop Med Hyg. 1984;33:862-71.

40. Kihara JH, Muhoho N, Njomo D, Mwobobia IK, Josyline K, Mitsui Y, et al. Drug efficacy of praziquantel and albendazole in school children in Mwea division, Central Province, Kenya. Acta Trop. 2007;102:165-71.

41. King $\mathrm{CH}$, Bertsch D. Meta-analysis of urine Heme dipstick diagnosis of Schistosoma haematobium infection. Including low-prevalence and previously-treated populations. PLoS Negl Trop Dis. 2013;7:e2431-10.

42. Hussain R, Ottesen EA. IgE responses in human filariasis, parallel recognition by IgE and IgG4 subclass antibodies. J Immunol. 1986;136:1859.

43. Khalife J, Dunne DW, Richardson BA, Mazza G, Thorne KJ, Capron A, Butterworth AE. Functional role of human $\lg G$ subclasses in eosinophil-mediated killing of schistosomula of Schistosoma mansoni. J Immunol. 1989;142(12):4422-7.

44. Walter K, Fulford AJ, McBeath R, et al. Increased human lgE induced by killing Schistosoma mansoni in vivo is associated with pretreatment Th2 cytokine responsiveness to worm antigens. J Immunol. 2006;177:5490-8.

45. Naus CW, Booth M, Jones FM, Kemijumbi J, Vennervald BJ, et al. The relationship between age, sex, egg-count and specific antibody responses against Schistosoma mansoni antigens in a Ugandan fishing community. Tropical Med Int Health. 2003;8:561-8.

Ready to submit your research? Choose BMC and benefit from:

- fast, convenient online submission

- thorough peer review by experienced researchers in your field

- rapid publication on acceptance

- support for research data, including large and complex data types

- gold Open Access which fosters wider collaboration and increased citations

- maximum visibility for your research: over $100 \mathrm{M}$ website views per year

At BMC, research is always in progress.

Learn more biomedcentral.com/submissions 